\title{
PERCURSO E DIVERSIDADE EPISTEMOLÓGICA DA PESQUI- SA EM EDUCAÇÃO: tensionamentos e possibilidades
}

\author{
ROUTE AND DIVERSITY EPISTEMOLOGICAL RESEARCH IN EDUCATION: ten- \\ sions and possibilities
}

CAMINOS Y DIVERSIDAD EPISTEMOLÓGICA DE LA INVESTIGACIÓN EN EDU-
CACIÓN: tensionamientos y posibilidades

Marcos Fernandes Sobrinho Professor Doutor do Instituto Federal Goiano - Campus Urutaí. marcos.sbf@gmail.com

Elisabete Alerico Gonçalves Professora Mestre do Instituto Federal Goiano - Campus Urutaí. Doutoranda em Epistemologia da História da Ciência, na UNTREF - Argentina. lisabete.alerico@ifgoiano.edu.br

Paula Silva Resende Fernandes Professora Mestre do Instituto Federal Goiano, campus Urutaí. paulinharesende2008@gmail.com

RESUMO: Faz-se uma breve revisão do percurso epistemológico dos métodos de pesquisa em educação à luz de alguns autores e seus contributos a partir do século XVII. Longe de qualquer pretensão no sentido de serem esgotadas as diversas direções dos estudos epistemológicos para pesquisa em Educação, enfocam-se contributos desses autores, especialmente, do Círculo de Viena, da Escola de Frankfurt e a Dialética de Marx. O papel da teoria do conhecimento é evocado com vistas a compor o debate acerca da diversidade metodológica frente à concepção hegemônica positivista de pesquisa. O trabalho aponta para o entendimento de que a metodologia de investigação em educação não se deve limitar à simples aplicação do que parecem sugerir os manuais de procedimentos e instrumentalização de pesquisa.

PALAVRAS-CHAVE: Métodos de pesquisa em educação. Epistemologia e pesquisa educacional. Procedimentos e instrumentalização de pesquisa.

ABSTRACT: It briefly reviews the epistemological course of research methods in education based on some authors and their contributions as of the seventeenth century. Far from any pretense in the sense of several directions of epistemological studies being exhausted for educational research, focus is on the contributions of these authors, especially from the Vienna Circle, the Frankfurt School and the Dialectic of Marx. The role of knowledge theory is summoned in order to make the debate about the methodological diversity against hegemonic positivist research design. Work points to the understanding that research methodology in education should not be limited to simple application to what seems to suggest procedure manuals and research instrumentalization.

KEYWORDS: Research methods in education. Epistemology and educational research. Procedures and research instrumentalization.

RESUMEN: Se hace una breve revisión del curso epistemológico de los métodos de investigación en educación a la luz de algunos autores y sus contribuciones a partir del siglo XVII. Lejos de toda pretensión con el fin de agotarse las distintas direcciones de los estudios epistemológicos para investigación en Educación, se enfocan contribuciones de estos autores, especialmente, del Círculo de Viena, de la Escuela de Frankfurt y la Dialéctica de Marx. El papel de la teoría del conocimiento es evocado con vistas a componer el debate relativo a la diversidad metodológica frente a la concepción hegemónica positivista de investigación. El estudio apunta para el entendimiento de que la metodología de investigación en educación no se debe limitar a la simples aplicación de lo que parecen sugerir los manuales de procedimientos e instrumentalización de investigación.

PALABRAS CLAVE: Métodos de investigación en educación. Epistemología e investigación escolar. Procedimientos e instrumentalización de investigación.

Artigo recebido em setembro de 2016

Aprovado em novembro de 2016 


\section{1| INTRODUÇÃO}

Muitos trabalhos acerca da problemática da pesquisa em ciências têm sido publicados com destaque para as questões em torno das técnicas, instrumentalizações e metodologias, em geral, com tendências focadas na concepção positivista para a pesquisa em Educação, que assume como pressupostos para a investigação, o empirismo lógico-dedutivo e regras de discursos hipotético-dedutivos.

Como se pretende apresentar, a diversidade de metodologias e das tendências epistemológicas que elucidam e focalizam a problemática educacional, parece não mais concordar com o pensamento positivista quanto ao "fazer" pesquisa em Educação.

Inicialmente são apresentados os critérios de demarcação científica à luz de alguns autores das ciências naturais, como: Popper, Descartes, Kant, Bacon, Locke, Hume, Mill, Schlick, Carnap, Feyerabend e Lakatos. Na sequência, as ideias da dialética, enquanto método possível para se conhecer a realidade concreta diante da dinâmica das inter-relações. A noção de dialética marxista, e o conceito dialético da totalidade, segundo a "Teoria Crítica", são trazidos com vistas a uma melhor compreensão a despeito da tese de que não há mais espaço para a defesa de que existam métodos únicos, sobretudo, com fulcro na concepção positivista, para o desenvolvimento de pesquisas em Educação.

\section{2 | CRITÉRIOS DE DEMARCAÇÃO CIENTÍFICA À LUZ DE ALGUNS AUTORES}

Reconhecido pela sua posição filosófica e originalidade acerca da ciência, Popper ficou conhecido pela sua "oposição oficial do Círculo de Viena" (NEURATH apud OLIVEIRA, 2012), posicionando-se criticamente em relação à tendência positivista. De acordo com seu pensamento, o conhecimento científico é sempre falível, conjectural e passível de erro e, por isso, adota a falseabilidade. Esse critério serve para demarcar as teorias científicas das teorias não científicas ou pseudocientíficas (OLIVEIRA, 2012). A proposta de Popper neste aspecto, é que as teorias sejam apoiadas, na pesquisa científica, na lógica dedutiva e não na indutiva, por conseguir demonstrar sua falseabilidade.

Enquanto a indução trata de vários casos particulares sem conseguir tornar uma teoria verdadeira, a dedução pode falseá-la com apenas um caso, devido sua lógica assimétrica ao partir do geral para o particular e, assim, aproximando da verdade. Neste contexto, o que se destaca em Popper é a defesa do racionalismo crítico que, diferente da atitude crítica, busca apenas a verdade, recorrendo à aplicação do modelo metodológico falseacionista. O que Popper pretende é mostrar o posicionamento a ser adotado na pesquisa para a obtenção de um resultado:

Inclino-me a afirmar que deveríamos tentar determinar o que eles [os cientistas] "devem"
["ought"] fazer. Esse "devem" obviamente não tem teor ético (embora a ética esteja também
envolvida aqui), mas seria antes o "devem" de um imperativo hipotético. A questão é: "Como
deveríamos proceder caso desejássemos contribuir para o crescimento do conhecimento
científico?" E a resposta é: "Você não tem melhor alternativa que proceder conforme o
método crítico de tentativa (conjectura) e eliminação do erro, procurando testar ou refutar
suas conjecturas." O argumento que suporta essa resposta pertence a lógica situacional.
Não penso que devemos nos voltar para a questão (sociológica) sobre o que os cientistas
realmente fazem ou dizem (POPPER, 1974b apud SANTOS in: OLIVEIRA, 2012, p. 137).

Dessa maneira, a base de tudo permanece sendo a racionalidade. Seu objetivo principal é elencar o sucesso da ciência ao método científico proporcionando seu uso às outras áreas do 
conhecimento. De acordo com Santos (in: OLIVEIRA, 2012, p. 138), "seu interesse não reside na procura de um método que espelhe um progresso efetivamente alcançado, mas sim na busca de uma metodologia que sustente processos de decidibilidade empírica, assegurando a crítica (leiase, a razão) no âmbito científico".

O texto de Popper intitulado "As origens do conhecimento e da ignorância", em Conjecturas e Refutações, remete-nos à ideia de que o pensamento clássico, do modo como era concebida a construção da Ciência, e cuja origem encontra-se alicerçada na concepção cartesiana de conhecimento, tem fulcro na ideia de que o conhecimento científico é construído a partir de proposições demonstradas. Essa construção pode se dar tanto por meio do intelecto, como defendiam os intelectualistas clássicos, a exemplo de Descartes (1596-1650) e Kant (1724-1804), ou por meio dos sentidos, como imaginavam os empiristas clássicos que têm Locke (1632-1704) e Hume (17111776) como exemplares. Essa vertente filosófica, a do Racionalismo Clássico, um Programa de Pesquisa, nitidamente justificacionista, predomina no pensamento científico dos Séculos XVII e XVIII e se apresenta com o núcleo central de que a natureza do conhecimento (ciência) é a verdade, e tem como principal característica a certeza.

Bacon, em sua perspectiva, afasta-se da visão cartesiana cuja fundamentação se localiza em um racionalismo rumo à verdade do conhecimento. Naquele momento, Bacon propõe o empírico, a ser observado na natureza, como fundamento último para se buscar um conhecimento verdadeiro. Para este autor, o que não for dessa maneira, deve ser entendido como pseudociência. Dessa forma, faz-se necessário um novo método científico, baseado na indução capaz de justificar as proposições. O caráter praxiológico, outra marca do pensamento baconiano, permite intervir e modificar a natureza. Enfatiza ainda, em seu texto, que os ídolos e as noções falsas devem ser abandonados/superados, vez que dificultam o acesso ao conhecimento verdadeiro.

Segundo Oliva (1990), em Epistemologia: a cientificidade em questão, a oposição à "especulação pseudocientífica", no século XVII, é entendida como uma das causas da valorização do método baseado na observação meticulosa e rigorosa de um fato. O método passa, então, a ser considerado como critério de demarcação entre ciência e metafísica. Este autor ainda considera que Bacon, na construção de seu método, abandonou três elementos de suma importância para a produção científica: i) a constituição de hipóteses para a definição do contexto de investigação; ii) as relações matemáticas dos conteúdos interpretativos; iii) a questão da imaginação criativa, que se manifesta nas teorias unificadoras de um campo experimental.

Para Schlick (1980), articulador do Círculo de Viena, representante do empirismo lógico e neo-positivistas extremado, não existe uma realidade transcendente, como quer a metafísica, mas somente o "dado" é real. Dessa forma, o debate sobre a realidade do mundo externo é uma pseudoquestão. O limite da significação, no entanto, pode ser apontado quando essa significação pode existir enquanto "dado". Essa captação do dado se dá pela sensação dos sentidos. A atividade da ciência consiste na verificação da verdade dos enunciados. O que conta é a possibilidade lógica da verificação, e não a sua exequibilidade. Desta feita, em seu trabalho, Moritz Schlick (1980) coloca que o verificacionismo tinha sido proposto como uma maneira de se compreender a ideia clássica de que a veracidade de uma frase consiste de sua correspondência com o fato.

Nesse sentido,

[...] a correspondência pode ser analisada como um procedimento verificacional constituída da comparação entre o conteúdo de uma hipótese e a experiência perceptiva que a verifica. Se houver identidade entre o conteúdo de ambas, a hipótese é verificada, caso contrário, ela é falseada [...] localizando essa correspondência dentro de um sistema de contextos linguísticos (SCHLICK, 1980, p. 81-84). 
Para este autor, esses são os pressupostos do conhecimento científico. Ou ainda, a verdade de um conteúdo consiste em sua correspondência com o fato, com a sua aceitação.

Porém, se compararmos com o modelo falseacionista e os parâmetros metodológicos dedutivistas de Popper, podemos dizer que há uma distinção ao que se refere aos enunciados básicos para que se corrobore ou refute uma hipótese, ou seja, contrário aos argumentos apresentados por Moritz Schlick, Popper diz que a aceitação desses enunciados não equivale à aceitação de "fatos".

Outra explicação na modalidade verificacionista, a qual estabelece que o significado de uma sentença factual resida no método de sua verificação experiencial, foi-nos oferecida por Carnap. Já em sua tese de doutorado "O Espaço: Uma Contribuição à Teoria da Ciência", de 1921, que mais tarde iluminara a "Construção Lógica do Mundo", de 1929, constitui a tentativa mais sistemática para sustentar a tese da ciência unificada. Como ele próprio ressaltou

[...] a distinção entre proposições significativas e não significativas, implicam necessariamente, a crença de que toda proposição científica pode, em última instância, reduzir-se a uma combinação de "enunciados protocolares" a partir de um sistema construcional (SCHLICK, 1980, p. 807).

Disso depreende-se que o significado de uma proposição consiste do princípio da verificação empírica (sentenças protocolares), o que gera, entre os partidários do Círculo, uma aparente sensação de consenso e segurança com os axiomas iniciais do empirismo lógico do Círculo de Viena.

É nesse contexto que, em algum momento, o então Programa Racionalista Clássico, torna-se degenerativo, vez que perde sua capacidade de resolver problemas. Nesse sentido, o indivíduo não tem mais acesso à verdade, mas simplesmente a um sistema de hipóteses. A partir disso, faz-se necessário refletir acerca de: como é possível a ciência sem o conhecimento direto da Verdade?

Então, alguns outros Programas surgem. O primeiro deles, o Programa Neorracionalista (ou Racionalismo Neoclássico), em que se propõe a fazer uma reconstrução da noção de racionalidade e que foi manipulada no período clássico, na medida em que se constrói todo um modelo de ciência para nos trazer decisões conclusivas acerca da verdade ou falsidade das proposições acerca do conhecimento. Essas proposições advinham do poder do intelecto, como assumiam e defendiam os intelectualistas, ou da evidência dos sentidos, como imaginavam os empiristas.

$\mathrm{Na}$ direção desse raciocínio analítico, o tradicional confronto entre o empirismo de Bacon, Locke, Berkeley, Hume e Mill e o racionalismo clássico ou intelectualismo de Descartes, Spinoza e Leibniz, desaparece, vez que o primeiro passa a ser interpretado como uma vertente do segundo, inserindo-se dentro deste último por meio de bases empíricas como fundamento da avaliação das proposições acerca do conhecimento.

Em vão, tenta-se salvar: (1) os princípios que norteiam o intelectualismo clássico a partir do redimensionamento que Ihe dá Kant (1724-1804); (2) a certeza de uma base empírica; (3) e a validade da inferência indutiva, que constituem as bases do empirismo clássico. No entanto, tudo isso não foi suficiente para a manutenção do Programa Racionalista Clássico, sendo colocado em cheque e que, portanto, sofre um duro golpe, imediatamente após as críticas de Hume (1711-1776) acerca do domínio de conhecimento abrangido por esse Programa. A partir daí, faz-se necessário pensar e propor a reelaboração de um novo racionalismo que seja ao menos compatível com o desenvolvimento científico da época.

Popper, dessa forma, reconhece o caráter hipotético, e sugere-nos o "caráter provisório" das proposições constituintes das teorias científicas. Propõe, então, a substituição da prova com certeza pela probabilidade como instrumento de avaliação do conhecimento. Nesse contexto, surge a inserção da noção de probabilidade no seio da Física, especificamente na Termodinâmica, em estudos sobre o comportamento dos gases, com o trabalho de Ludwig Boltzmann (1844-1906). 
Apenas depois dessa noção de probabilidade ser introduzida na ciência como medida epistêmica, com trabalhos de Rudolf Carnap (1891-1970) que, por meio dela, passa a ser elaborada uma nova concepção de racionalidade científica cuja base se pauta no modelo de decisão com incerteza. É, nessa perspectiva, que se tem caracterizado um novo programa de pesquisa, o Programa Neorracionalista, que marca um avanço no sentido da manutenção da ideia atrelada à da racionalidade no empreendimento científico. Faz-se necessário um novo critério de demarcação e Popper o propõe.

Assim, surge o Falseacionismo, que passa a redimensionar os critérios de construção e avaliação das teorias científicas, estabelecendo, portanto, padrões novos de honestidade intelectual, enfatizando a defesa da ciência enquanto empreendimento racional, muito embora não se constituindo como certeza, última palavra. E é este o momento em que se desfere, por completo, o ataque ao programa racionalista clássico, vez que agora ele é dirigido tanto ao fundamento último, no qual se constituía as proposições verdadeiras dos intelectualistas clássicos, quanto ao que se constituía a base empírica dos empiristas clássicos, embora esta última ainda continue desempenhando um papel importante a partir de seu redimensionamento.

Dessa maneira, numa espécie de desfecho parcial, Popper sugere que somente os argumentos dedutivos são legítimos e que, portanto, o método da ciência não se faz a partir de acumulação de evidências, mas de conjecturas e refutações.

Nesse sentido, Popper, contemporâneo do enfraquecimento da mecânica e da teoria newtoniana, diante do surgimento da física moderna e contemporânea (teoria da relatividade e da mecânica quântica), contrapõe-se clara e veementemente ao positivismo e a toda teoria que remete ao dogmatismo. Advoga que o conhecimento é falível e passa por correções que se dão em ciclos temporais. Opõe-se ao raciocínio dedutivo e indutivo tomando a ciência como conjectural. Desta forma, a garantia da pesquisa se ampara no falseacionismo de hipóteses em que o conhecimento toma, então, dimensões distintas ao longo do tempo (POPPER, 2011).

Por meio do falseacionismo, Popper afirma que uma teoria apenas será rejeitada por falsificação a partir do momento que surgir outra que a satisfaça, ou seja, que apareça outra teoria melhor. É dizer que, "la ciencia crece por sucessivas conjeturas y refutaciones" (MELLADO; CARRACEDO, 1993, p. 333). Nesse sentido, López-Ruperez (1990), apresenta as afirmações de Lakatos (1983), deixando claro quais são as condições para que uma teoria seja faseada por outra:

\footnotetext{
[...] 1) T' possui um excesso de conteúdo empírico em relação a T, isto é, prevê novos fatos improváveis ou excluídos dos T; 2) T explica o sucesso prévio de T, isto é, todo o conteúdo não refutado de T está incluído (dentro dos limites de erro de uma observação) no conteúdo de T; 3) uma parte do excesso de conteúdo de T' é corroborado (LAKATOS, 1983 apud MELLADO; CARRACEDO, 1993, p. 68).
}

Esse argumento tem possibilitado uma mudança de postura no âmbito da educação científica, de extrema relevância na pesquisa em educação, pois pode propor ações que estimulem os conflitos cognitivos entre as concepções rivais. Para Lakatos, todo programa de investigação científica tem um núcleo central resistente às mudanças, e no máximo que a ser alcançado com a falsificação é a rejeição das hipóteses auxiliares que podem ser substituída sem alterar o essencial. Dessa maneira, o progresso científico se produziria pela competência entre os programas, de tal maneira que simultaneamente fosse verificado as desvantagens do velho e as vantagens do novo, avaliando-se o progresso ou a degeneração dos mesmos.

A partir desta concepção sobre o método e o conhecimento que se quer, Lakatos propõe uma reflexão paralela sobre o tipo de aprendizagem científica de que se está tratando. Conforme menciona Gil-Pérez (1986, p.115), é preciso superar a "metodología de la superficialidad". Então, os 
os resultados obtidos na pesquisa em educação também estão relacionados a imagem que é criada da ciência através da educação científica.

Feyerabend (1985), em seu livro Contra o método, "anarquiza" posicionando-se contra a tradição da concepção empirista de ciência e não vê a demarcação científica como um problema a ser enfrentado e dá espaço à sociologia da ciência e psicologia da criação. Pelo seu princípio da proliferação, deve ser apresentado o maior número possível de teorizações, pois amplia o universo de fatos testadores da teoria patrocinada. Vê a proximidade entre conhecimento científico e mito, adotando a máxima de que "tudo vale". Nesse movimento, o autor faz uma crítica às metodologias e ao processo de produção do conhecimento até então utilizado. Coloca-se contrário à instituição de um único e limitado conjunto de regras para ser aplicado em todas e quaisquer situações, o que justifica a concepção dita anarquismo metodológico. Questiona-se a veracidade e a capacidade de auferir a verdade absoluta dos métodos, em contraposição à capacidade de se elaborar um método capaz de conter princípios firmes e absolutamente cristalizados. Desta forma, questiona o conceito de ciência e defende uma pesquisa que dialogue com outras disciplinas (FEYERABEND, 1985). Vê no justificacionismo, através do contexto da descoberta e da justificação, uma relação de extrema importância para a ciência a partir do momento que interagem. Dessa maneira, sua proposta de teor anárquico, propõe uma valorização de outros contextos não-científicos, sem destaque para uma teoria dominante, promovendo maior liberdade. Essa liberdade dada ao cientista permite o progresso da ciência.

Para Feyrabend (1985), a ciência ao longo da história,

[...] criou uma tradição que se mantém una ou intacta, graças à observância de regras restritas, e que, até certo ponto, alcança êxito. Mas será desejável dar apoio a essa tradição, em detrimento de tudo mais? Devemos conceder-lhe direitos exclusivos de manipular o conhecimento, de tal modo que quaisquer resultados obtidos por outros métodos sejam, de imediato, ignorados? Esta é a indagação a que pretendo dar resposta neste ensaio. E minha resposta será um firme e vibrante NÃO (FEYERABEND, 1985, p. 21-22).

Portanto, Feyerabend (1986), nega então, a existência de um conhecimento científico universal. Parte do contexto de que há diferentes tipos de ciência e de conhecimento científico de acordo com as diferentes culturas e os diferentes contextos sociais em que a própria ciência se desenvolve.

De acordo com Kuhn (2010), alguns conceitos ocupam lugar de destaque como o de "paradigma" - é aquilo que os membros de uma comunidade partilham e, inversamente, uma comunidade científica consiste em homens que partilham dele; o de "ciência normal" - período dentro de um dado paradigma que é adotado por uma comunidade científica; a "anomalia" - quando o paradigma não resolve, ultrapassa o controle e instala-se uma crise que só será resolvida por outro paradigma; e "revolução" - criam-se novos paradigmas, quando em nível individual (conversão), processo da ciência normal até outra crise. Esse autor lança mão da história da ciência para explicar as mudanças, em uma perspectiva de descrição positiva e a aceitação de um novo paradigma não se dá por questões racionais, a partir de um processo interno de praticar a pesquisa, mas representa uma conversão irracional por parte da comunidade científica. Enfatiza o caráter revolucionário do próprio progresso científico.

Nesse sentido, as mudanças são afloradas de tempo em tempo e o progresso se dá por meio de saltos. As crises, então, são estabelecidas, acompanhadas de uma revolução científica. No entanto, há uma caracterização anterior a esta, caracterizado e decorrente de desacordos e de discussões acerca de fundamentos. Realça a grande importância dos paradigmas, vez que determinarão novos padrões de conhecimento que coordenarão e dirigirão formas como os pesquisadores trabalharão. Dessa forma, a revolução científica se constitui de um período de mudança de 
paradigmas que tem como desdobramento, alteração da forma como se interpreta o mundo (KUHN, 2010).

Lakatos (1979) apresenta a ponderação de que são necessários "novos processos purificadores adicionais" [...]. O problema não deveria ser colocado, em termos de se saber se uma 'refutação' é real ou não. [...]. O problema é saber que teoria considerar interpretativa (fatos 'concretos') e que teoria como explanatória ('tentativamente os explica)". Assim, conforme Lakatos (1983), o caráter progressivo das teorias está relacionado com o critério de demarcação ou regras de aceitação de uma teoria científica e, com a própria explicação adequada da racionalidade.

Nessa perspectiva, a reflexão sobre o progresso da ciência só é relevante, epistemologicamente, quando realizado sob "programas de pesquisa". Assim, para ele, um "programa de pesquisa será bem-sucedido se tudo isso conduzir a uma transferência progressiva de problemas, porém, mal sucedido se conduzir a uma transferência degenerativa de problemas". Entenda-se transferência progressiva como sendo o aumento de conteúdo (ou transferência de problemas) teórico e empírico (intermitentemente progressiva).

O autor também coloca que "poucos cientistas teóricos empenhados num programa de pesquisa, ao longo prazo, dão indevidas atenções às 'refutações'”. O programa de pesquisa tem duas heurísticas, que é o conjunto de regras metodológicas, cuja função é indicar qual rota de investigação devem ser seguidas (LÓPEZ RUPÉREZ, 1990), sendo elas: "heurística positiva" (flexível e avança aos poucos), entendida como a forma de desenvolver, sofisticar e proteger a teoria com modelos que simulam a realidade (exercício de "refutação") com "variantes refutáveis" (impedindo que o cientista se perca num "oceano de anomalias"), formam um "cinturão protetor" do "núcleo" da teoria; e a "heurística negativa" (menos flexível) que impede a refutação do "núcleo", que é "irrefutável" por decisão metodológica, ignorando os "dados" disponíveis. Desvia a vontade dos pesquisadores para o cinturão protetor, o qual pode ser ajustado, parcialmente, ou totalmente substituído. Para ele, substituir os "programas de pesquisa" pelo "behaviorismo epistemológico" é demonstrar desconhecimento do "estado da arte" da epistemologia.

Realisticamente conclui que

[...] a metodologia dos programas de pesquisa científica explica a relativa autonomia da ciência teórica [...] [porque] os programas de pesquisa são determinados pela heurística positiva do programa (LAKATOS, 1979, p.168).

Desse ponto, suscita outro problema relevante, qual seja: "como são eliminados os programas de pesquisa?". A forma é a seguinte: "um programa de pesquisa rival que explica o êxito anterior de seu rival e o suplanta por uma demonstração adicional de força heurística". A partir daí, programas rivais, pouco a pouco, invadem o território uns dos outros. O autor denomina esse processo no qual um programa novo enxerta-se em um programa velho de "simbiose competitiva". Diante de tal ocorrência afirma que "o status de uma experiência tão 'crucial' depende do status da competição teórica em que se acha envolvida". Por óbvio que há diferença entre "simbiose competitiva" e "conversação" entre cientistas.

Nesse sentido, ressalta-se que, quando um programa de pesquisa consegue alcançar sua cota máxima de crescimento, não só serviu para oferecer um marco teórico com um alto poder explicativo, mas que também influenciou desde a visão conceitual, metodológico e terminológicos posteriores, pois deve ser capaz de explicar, pelo menos, o essencial dos resultados obtidos (LÓPEZ-RUPÉREZ, 1990).

Assim, na perspectiva dos programas de pesquisa, ensina-nos a perder a ingenuidade de acreditar que existem experiências cruciais, 
[...] capazes de derrubar instantaneamente um programa de pesquisa. [Todavia, ocorre que] quando um programa de pesquisa sofre uma derrota e é suplantado por outro, podemos - numa longa visão retrospectiva - chamar crucial a uma experiência se verificar que ele propiciou uma corroboração espetacular do programa vitorioso e o fracasso do programa derrotado (LAKATOS, 1979, p. 216).

A conclusão da conclusão desse autor nos ensina, mais uma vez, que a Coruja de Minerva voa ao cair da noite.

[...] A continuidade da ciência, a tenacidade de algumas teorias, a racionalidade e certas doses de dogmatismo só poderão ser explicados se interpretarmos a ciência como um campo de batalha onde pelejam programas de pesquisa muito mais do que teorias isoladas (LAKATOS, 1979, p. 216).

Então, finaliza: ciência madura consiste em programas de pesquisa:

[...]. Ciência madura - à diferença do ensaio-e-erro corriqueiro - tem força 'heurística'. Assim, se o "behaviorismo epistemológico" continua existindo, apesar de não explicar nada a respeito dos "programas de pesquisa", se deve a "conversação" inútil entre cientistas isolados, fora da "ciência madura" (LAKATOS, 1979, p. 217).

Segundo Imre Lakatos (1979), a lógica da descoberta científica de Popper funde duas distintas posições acerca do conhecimento científico, a saber: o "Falseacionismo Ingênuo" (que ele prefere denominar "Falseacionismo Metodológico Ingênuo") e o "Falseacionismo Sofisticado", que incorpora uma racionalidade ampliada, e por isso mesmo mais eficaz.

Com efeito, Lakatos demonstra ser possível, a partir de seus argumentos, a compreensão da "racionalidade científica" da produção dos cientistas, no interior de uma "ciência madura". Parece evidente que Lakatos segue Popper (do falseacionismo dogmático/ingênuo ao falseacionismo metodológico), mas o supera com a invenção epistemológica da ideia dos "programas de pesquisa", levando a crer que consegue desenvolver uma epistemologia capaz de elucidar a "rotina" do "como" se faz ciência, de maneira "normativa" com "óculos popperiano".

Lakatos (1970) aborda que os "fatos" não apoiam as teorias, mas sim os "programas de investigação científica - PIC", por esse motivo quando o cientista que se defrontar com refutações ao seu programa deve, quando necessário, fazer alterações nas hipóteses auxiliares, resguardando o núcleo do programa. Essas hipóteses auxiliares constituem o cinturão protetor do núcleo mantendo o andamento da pesquisa. Sua metodologia mostra a importância do estudo histórico de qualquer caso ligado à história da ciência tendo a preocupação em promover uma descrição racional com a realidade, por isso, seu programa de investigação é historiográfico.

Como as construções racionais não são tão ricas como a história da ciência, sua metodologia precisa ser completada por uma história empírico-externa. Para Lakatos (1970), independente da noção que se tenha de verdade, deve haver racionalidade metodológica no processo de desenvolvimento do conhecimento; conhecimento este, que servirá como crescimento em um processo de progresso. Sua noção de progresso liga-se ao requisito de Leibniz-Whewell-Popper de que a construção das 'caixinhas' deve anteceder o registro dos fatos que deverão ser colocados nelas (LAKATOS, 1970, p. 100), e, portanto, depende crucialmente da noção de fato novo. 


\section{3 | A DIALÉTICA ENTENDIDA COMO MÉTODO POSSÍVEL PARA DESCRIÇÃO DA REALI- DADE CONCRETA}

Vários são os tipos de dialética. Neste estudo, apenas a dialética compreendida como método capaz de nos possibilitar desvelar a realidade concreta diante dos aspectos dinâmicos das inter-relações. De acordo com Marx (1983), em sua obra "Método da Economia Política", publicada em 1983, a dialética é apresentada, com o processo de construção do concreto do pensamento, partindo-se do concreto real. Trata-se da síntese de múltiplas determinações mais simples, mais abstratas, no pensamento, e que vão compondo a construção do concreto. Fala-se em concreto pelo fato de ser uma síntese que se desdobra em uma unidade do diverso, o que não pode ser confundido com o ponto de partida. Ainda, há que se falar que o concreto não é o dado empírico, mas uma articulação que se constrói o todo.

A dinâmica da lógica dialética se propõe a enunciar as leis que governam o real. Para a escola de Frankfurt, Adorno e Habermas, entendem que o importante para o conhecimento é a crítica e o conceito dialético da totalidade. Fala-se aqui em, respectivamente, "Razão Crítica" e "Razão Dialética" e nesse sentido, a crítica dos interesses e a emancipação do homem compõem a tarefa maior da ciência.

Habermas parte da recusa ao modelo positivista feita pelo próprio Popper. Critica a indução, a verificabilidade, a identificação da importância do papel do pesquisador, a inserção em uma comunidade científica que é condicionada cultural e historicamente. No entanto, este autor não concorda com a objetividade científica e então continua a defender.

Críticas de Habermas à Popper:

(1) Crença na autonomia do mundo em relação aos sujeitos que produzem; (2) Os fatos são os que decidem a veracidade das hipóteses; (3) Verdade como adequação na realidade, já que as teorias que buscam se aproximar de uma concepção adequada é uma realidade pensada independente dos sujeitos; (4) Seu caráter meramente de decisão, não passível de justificação racional ou atitude crítica; (5) Sua redução a um conceito de racionalidade estreito que se reduz ao processo dedutivo de fazer combinações e de produzir refutações. Ou seja, se reduz ao julgamento e ao erro no sentido de confronto com os fatos; (6) Sua concepção do sujeito do conhecimento como um ser isolado, dotado de consciência individual (ARAGÃO, 2002, p. 78).

Desta feita, a abordagem epistemológica auxilia a recuperação de implicações ideológicas nos diversos paradigmas científicos que, para Habermas (1983), compõem o campo de interesses humanos que objetivam os variados tipos de conhecimento. Para Bachelard (1968), ao contrário do que propõem os positivistas separando a filosofia da ciência, sugere o caminho da reflexão sobre

Já Habermas (1982), propõe uma reflexão capaz de recuperar as relações da ciência com o histórico da sociedade e com a filosofia. É essa filosofia que se mostra ao alcance de reabilitar o papel crítico da teoria do conhecimento e reinserir as ciências na totalidade social.

Retomando a contribuição de Kuhn frente ao delineamento de aparatos instrumentais para a pesquisa em educação, este autor introduz na literatura científica o conceito de "paradigma" com o propósito de elucidar o processo histórico das ciências. Para ele, as ciências avançam por meio de revoluções, quando a intitulada "ciência normal" não se presta a dar explicações à totalidade dos fenômenos descobertos. Segundo Kuhn (2010), o modelo vigente se mostra em crise, tornando-se necessário o desenvolvimento de um novo modelo ou paradigma que substitui aquele. Essa mudança para o novo modelo ou paradigma só é possível a partir do estabelecimento de uma nova estruturação da ciência. as filosofias implícitas nas práticas científicas explícitas, recuperando, desta forma, a filosofia que cada ciência merece. 
Há que se atentar, pelo que se pretende no presente trabalho, aos diversos valores polissêmicos atribuídos ao conceito de paradigma na obra de Kuhn. Desta feita, a noção de paradigma em ciências humanas não pode ser a mesma nas ciências físicas e naturais. Nesse sentido, Masteman (1979) nos lembra que nas ciências psicológicas, sociais e da informação há uma ciência multiparadigmática, o que nos parece sugerir uma visão mais ampla e global, diante dessa característica e da comumente substituição dos anteriores pelos novos modelos, em comparação à viso rígida, formal e precisa das ciências exatas.

\section{4 | CONSIDERAÇÕES FINAIS}

O debate acerca do que dizem esses autores, aqui trazidos, certamente contribui não apenas para melhor compreensão de como as diferentes concepções sobre o "fazer ciência" à luz dos tensionamentos provenientes das defendidas por eles, no campo da demarcação científica e não-científica.

O marxismo e a dialética, embora tenham se afirmado como teorias e métodos com considerável capacidade heurística, vez que se aproximam do interesse transformador, ainda é grande o número de questionamentos de pesquisa que utilizam categorias do marxismo. A literatura tem apontado, entre outros aspectos, falta de rigor metodológico e de compreensão das pretensas fundamentações com bases epistemológicas e filosóficas.

No campo epistemológico, dentro do contexto das ciências sociais e humanas, parece ser razoável o entendimento de que cada enfoque epistemológico se mostra diferentemente especial ao conceber processos de desenvolvimento de pesquisas em educação, de acordo com a forma que se buscam relacionar o real com o abstrato e o concreto.

Face ao exposto é possível descobrir maneiras distintas para relacionar o sujeito e o objeto ao longo do processo de desenvolvimento de uma investigação em educação e, desse modo, o presente trabalho aponta para o entendimento de que a metodologia de pesquisa em educação não se deve limitar à simples aplicação do que parecem sugerir os manuais de procedimentos e instrumentalização de pesquisa. 


\section{Referências}

ARAGÃO, L. Habermas: filósofo e sociólogo do nosso tempo. Rio de Janeiro: Tempo Brasileiro, 2002.

BACHELARD, G. A formação do espírito científico. (La formation de l'esprit scientifique). Trad. de Juvenal Hahne Júnior. Rio de Janeiro, Biblioteca Tempo Universitário, 1968.

FEYERABEND, P. Contra o Método. Rio de Janeiro: F. Alves Editora, 1985.

FEYERABEND, P. Tratado contra el método. Esquema de una teoría anarquista del conocimiento. Madrid, Tecnos, 1986.

GIL-PÉREZ, D. La metodología científica y la enseñanza de las ciencias: unas relaciones controvertidas. Enseñanza de las Ciencias, v. 4, n. 2, 1986, p. 111-121.

HABERMAS, J. Teoria de la acción comunicativa: complementos y estudios previos. Madrid: Cátedra, 1982

HABERMAS, J. Para a reconstrução do materialismo histórico. São Paulo: Brasiliense, 1983.

KUHN, T. S. A estrutura das revoluções científicas. Tradução: Beatriz Vianna Boeira e Nelson Boeira. 10. Ed. São Paulo: Perspectiva, 2010.

LAKATOS, I. O Falseamento e a Metodologia dos Programas de Pesquisa Científica. In: A Crítica e o Desenvolvimento do Conhecimento. (Org.): Imre Lakatos e Alan Musgrave. São Paulo: Cultrix: Edusp, 1979.

LAKATOS, I.; MUSGRAVE, A. (eds). La critica y el desarollo del conocimiento. Barcelona: Grijalbo, 1970.

LÓPEZ-RUPÉREZ, F. Epistemología y didáctica de las ciencias. Un análisis de segundo orden. Enseñanza de las Ciencias, en prensa, 1990.
MARX, K. O método da economia Política. In: Contribuição à crítica da economia política. São Paulo: Martins Fontes, 1983. p. $218-232$.

MASTEMAN, M. A Naturaleza do Paradigma. In: LAKATOS, I; MUSGRAVE, A. (Orgs). A crítica e o Desenvolvimento do Conhecimento. São Paulo: Cultrix, 1979, p. $72-108$

MELLADO, V.; CARRACEDO, D. Contribuciones de la filosofia de la ciencia a la didáctica de las ciencias. Enseñanza de las Ciencias, 11 (3), 331-339, 1993.

OLIVA, A. (org.) Epistemologia: a cientificidade em questão. São Paulo: Papirus, 1990.

OLIVEIRA, P. E. de (org.). Ensaios sobre o pensamento de Karl Popper. Curitiba: Círculo de Estudos Bandeirantes, 2012.

POPPER, K. R. As origens do conhecimento e da ignorância. In: POPPER, K. R. Conjecturas e refutações. 5 ed. Brasília. Editora UnB, 2008.

POPPER, K. R. A lógica da pesquisa científica. São Paulo: Cultrix, 2011.

SCHLICK, M. Positivismo e Realismo. In: Schlick-Carnap. São Paulo: Abril Cultural (Coleção Os pensadores), 1980.

O Fundamento do Conhecimento. In: Schlick-Carnap. São Paulo: Abril Cultural (Coleção Os pensadores), 1980. 